\title{
Pyrrolidone Modifying Gold Nanocatalysts for Enhanced Catalytic Activities in Aerobic Oxidation of Alcohols and Carbon Monoxide
}

\author{
Yingji Song, ${ }^{1}$ Xuefeng Chu, ${ }^{1,2}$ Yingzi Lin, ${ }^{3}$ and Xiaotian Yang ${ }^{2}$ \\ ${ }^{1}$ Department of Basic Science, Jilin Jianzhu University, Changchun 130118, China \\ ${ }^{2}$ Jilin Provincial Key Laboratory of Architectural Electricity \& Comprehensive Energy Saving, School of Electrical and \\ Electronic Information Engineering, Jilin Jianzhu University, Changchun 130118, China \\ ${ }^{3}$ Key Laboratory of Songliao Aquatic Environment, Ministry of Education, Jilin Jianzhu University, Changchun 130118, China \\ Correspondence should be addressed to Xiaotian Yang; hanyxt@163.com
}

Received 21 February 2017; Revised 6 May 2017; Accepted 23 May 2017; Published 6 July 2017

Academic Editor: Cristina Femoni

Copyright (C) 2017 Yingji Song et al. This is an open access article distributed under the Creative Commons Attribution License, which permits unrestricted use, distribution, and reproduction in any medium, provided the original work is properly cited.

Enhancing the catalytic activity of supported metal nanoparticle is a great demand but extremely challenging to make. We reported a simple strategy for enhancing the activities by employing the polyvinylpyrrolidone (PVP) additive, where a series of supported Au nanoparticle catalysts including $\mathrm{Au} / \mathrm{C}, \mathrm{Au} / \mathrm{BN}, \mathrm{Au} / \mathrm{TiO}_{2}$, and $\mathrm{Au} / \mathrm{SBA}-15$ exhibited significantly higher activities in the oxidation of various alcohols and carbon monoxide by molecular oxygen after adding PVP to the reaction system. The XPS study indicates that PVP could electronically interact with Au to form high active Au sites for molecular oxygen, thus causing improved activities for the various oxidation reactions.

\section{Introduction}

Since the pioneer work of Haruta and Hutchings [1-6], Au catalysts have been demonstrated to be promising catalysts for various reactions, including aerobic oxidation [710], homocoupling [11-14], and selective hydrogenation [1518]. Particularly, the oxidation of hydrocarbons including alcohols [19] and olefins and alkanes [20, 21] has attracted much attention. However, the catalytic activities of the gold nanoparticles are always unsatisfactory, which limited their wide application. A key step in the Au-catalyzed oxidation reactions is the activation of molecular oxygen on Au surface. Many parameters of the Au nanoparticle catalysts have been well understood to be sensitive for their catalytic activities to molecular oxygen, such as the nanoparticles sizes [22], valence state [23], and strong metal-support interactions [24]. However, rationally controlling the factors for the goals of high catalytic activity in oxidation is still challenging.

In recent years, much success has been achieved in synthesizing active Au catalysts. For examples, Turner et al. synthesized ultrasmall Au nanoclusters exhibiting high activity in the activation of molecular oxygen [25]; Wang et al. synthesized 2D-Au nanostructure with layer thickness and rich low-coordinative $\mathrm{Au}$ atoms, which is very active in the activation of molecular and oxidation of carbon-hydrogen bonds [26]. Notably, these methods are mainly focused on changing the size and morphology of the Au nanoparticles, which are difficult in synthesizing these catalysts as well as controlling their stability. Constructing strong interaction between $\mathrm{Au}$ nanoparticles and the support is regarded to be effective in creating highly active metal sites for the oxidation, which has been widely used in the $\mathrm{Au} / \mathrm{TiO}_{2}$ [27], $\mathrm{Au} /$ hydrotalcite [28], and Au/organic polymer [29] catalysts. In these cases, an important discovery in this field is that the polyvinylpyrrolidone (PVP) could strongly interact with the soluble Au nanoparticles in water solvent, leading to high activity in oxidation of alcohols [30,31]. Up to date, much attention has been focused on PVP-stabilized nanoparticles as soluble catalysts [32], because PVP is cheap, harmless, and easily available. However, this system has disadvantage in the separation and regeneration of the soluble $\mathrm{Au}$ nanoparticles. Notably, the employment of PVP additive is 
rarely reported for the Au nanoparticles supported on solid support $[30,31]$. It is still uncertain whether the PVP additive would work for the supported $\mathrm{Au}$ nanoparticle catalysts. Herein, we systemically studied the effect of PVP additive for various supported $\mathrm{Au}$ catalysts of $\mathrm{Au} / \mathrm{C}, \mathrm{Au} / \mathrm{BN}, \mathrm{Au} / \mathrm{TiO}_{2}$, and Au/SBA-15. Interestingly, the addition of PVP could significantly enhance the catalytic activity of these catalysts in the oxidation of alcohols and CO. Particularly, the Au/SBA15 presented the highest activity compared to other catalysts due to the mesoporous structure of SBA-15 support, which facilitates the adsorption/enrichment of the PVP species and promotes the PVP-Au interaction.

\section{Experimental}

2.1. Materials. All reagents were of analytical grade and used as purchased without further purification.

2.1.1. Synthesis of SBA-15. The mesoporous silica of SBA15 was synthesized according the method in literature [33]. As a typical run, $0.82 \mathrm{~g}$ of copolymer surfactant P123 was dissolved in $24 \mathrm{~mL}$ of water with $3 \mathrm{~mL} \mathrm{HCl}(12 \mathrm{M})$, followed by the addition of $2.4 \mathrm{~mL}$ TEOS (tetraethyl orthosilicate). After stirring at $40^{\circ} \mathrm{C}$ for $20 \mathrm{~h}$, the mixture was transferred into an autoclave for further condensation at $100^{\circ} \mathrm{C}$ for $24 \mathrm{~h}$. The assynthesized samples were collected by filtration and calcined at $500^{\circ} \mathrm{C}$ for $4 \mathrm{~h}$ in oxygen to remove the surfactants.

2.1.2. Synthesis of $A u / T_{i O}, A u / S B A-15, A u / C$, and $A u / B N$. These catalysts were synthesized by the classic impregnation method [34]. As a typical run for the synthesis of $\mathrm{Au} / \mathrm{TiO}_{2}$, $1 \mathrm{~g}$ of anatase was added to $80 \mathrm{~mL}$ of $\mathrm{HAuCl}_{4}$ and urea solution. After stirring at $90^{\circ} \mathrm{C}$ for 4 hours in a closed reactor kept away from the light, the liquid mixture was cooled in an ice bath at $0^{\circ} \mathrm{C}$, followed by adding $\mathrm{NaBH}_{4}$ solution ( $50 \mathrm{mg}$ of $\mathrm{NaBH}_{4}$ in $6 \mathrm{~mL}$ of water). Finally, the solid sample was filtrated and washed with a large amount of water, dried at $100^{\circ} \mathrm{C}$ for 12 hours, and calcined at $400^{\circ} \mathrm{C}$ for 4 hours, obtaining the final $\mathrm{Au} / \mathrm{TiO}_{2}$ catalyst. By using activated carbon $\left(\mathrm{HNO}_{3}\right.$ treatment to change the surface to be hydrophilic) and $\mathrm{BN}$ (boron nitride) as support, $\mathrm{Au} / \mathrm{C}$ and $\mathrm{Au} / \mathrm{BN}$ were synthesized in the same method.

2.1.3. Synthesis of PVP-Modified $\mathrm{Au} / \mathrm{TiO}_{2}, \mathrm{Au} / \mathrm{SBA}-15, \mathrm{Au} / \mathrm{C}$, and $A u / B N$. As a typical run for the synthesis of PVPmodified Au/SBA-15, $1 \mathrm{~g}$ of SBA-15 and $80 \mathrm{mg}$ of PVP were mixed in a mixture of $10 \mathrm{~g}$ of water and $10 \mathrm{~g}$ of ethanol. After stirring at room temperature for $6 \mathrm{~h}$ and removing the liquor under vacuum at $60^{\circ} \mathrm{C}$, the PVP-modified Au/SBA- 15 was obtained.

2.2. Characterization. X-ray photoemission spectroscopy (XPS) measurements were carried out using a Thermo Fisher Scientific ESCALAB 250i with photoelectron spectroscopy system using a $300 \mathrm{~W}$ monochromatic $\mathrm{Al} \mathrm{K} \alpha(1486.6 \mathrm{eV}) \mathrm{X}$ ray source. The instrument work function was calibrated to give an $\mathrm{Au} 4 \mathrm{f}_{7 / 2}$ metallic gold binding energy (BE) of $83.96 \mathrm{eV}$. The spectrometer dispersion was adjusted to give a $\mathrm{BE}$ of $368.21 \mathrm{eV}$ for metallic $\mathrm{Ag} 3 d_{5 / 2}$ and $932.62 \mathrm{eV}$ for metallic
$\mathrm{Cu} 2 p_{3 / 2}$. The XPS spectra were collected in constant analyzer energy (CAE) mode. Instrument base pressure was $2.0 \times$ $10^{-10}$ mbar and high-resolution spectra were collected using a spot size of $500 \mu \mathrm{m}$, with pass energy of $20 \mathrm{eV}$. The charge neutralization being monitored using the $\mathrm{C} 1$ s $(284.6 \mathrm{eV})$ signal for adventitious carbon. Thermogravimetric curves (TG) were performed on a SDT Q600 Simultaneous DSCTGA in flowing air with heating rate of $10^{\circ} \mathrm{C} / \mathrm{min}$. In the TG curves, the weight loss during the $400-600^{\circ} \mathrm{C}$ is regarded to be the loss of PVP species. The weight loss weight percentage is $6.3 \%$ over the PVP-modified $\mathrm{Au} / \mathrm{TiO}_{2}$, while the loss weight percentage is only $\sim 1.0 \%$ over the PVP-free $\mathrm{Au} / \mathrm{TiO}_{2}$ sample. The adsorption amount of PVP on the solid sample was tested with $0.5 \mathrm{~g}$ of solid sample in a PVP solution ( $30 \mathrm{~mL}$ water and $0.2 \mathrm{~g}$ of PVP). The adsorption amount was measured by a weight method. The high-resolution transmission electron microscopy (HR-TEM) was over a JEOL JEM3000F microscope. ICP (Inductive Coupled Plasma Emission Spectrometer) has been used to measure the $\mathrm{Au}$ content $[26,35]$. As a typical run for analyzing the Au loading on $\mathrm{Au} / \mathrm{SBA}-15$, the solid samples were dried at $120^{\circ} \mathrm{C}$ under vacuum overnight, then $\sim 13 \mathrm{mg}$ of the sample (the amount was precisely measured) was digested in a mixed aqueous solution of $\mathrm{HF}, \mathrm{HNO}_{3}$, and $\mathrm{HCl}$. The suspension was heated at $35^{\circ} \mathrm{C}$ for completely dissolving the sample. Then the solution was diluted to $100 \mathrm{~mL}$. For each sample, the Sn content was tested at least five times. The Au contents were calculated by the mean value. The Sn content in the solid sample was calculated from the concentration according to the following equation:

$$
P_{\mathrm{Au}}=\left[\frac{\left(C_{\mathrm{Au}} * V_{\text {solution }}\right)}{W}\right] * 100 \% .
$$

where $P_{\mathrm{Au}}$ is the weight percentage of Au in the solid sample, $C_{\mathrm{Au}}$ is the concentration of Au measured by ICP, $V_{\text {solution }}$ is $100 \mathrm{~mL}$, and $W$ is the amount of solid sample for preparing the solution.

2.3. Catalytic Tests. Catalytic oxidation of alcohols was performed in a $40-\mathrm{mL}$ high-pressure autoclave with a magnetic stirrer (commercially obtained from the Xinyu Co.). The substrate and catalyst were mixed in the reactor and oxygen was introduced, and then the reaction system was heated to a given temperature. After the reaction, in the catalytic tests, the product was taken out from the reaction system and analyzed by gas chromatography (GC-14C, Shimadzu, using a flame ionization detector) with a flexible quartz capillary column (length at $100 \mathrm{~m}$ ) coated with FFAP (free fatty acid phase). The columns are localized in a programmed temperature control system, where the temperature started at $60^{\circ} \mathrm{C}$ and increased to $200^{\circ} \mathrm{C}$ at a rate of $10^{\circ} \mathrm{C} / \mathrm{min}$ and then kept at $200^{\circ} \mathrm{C}$ for $45 \mathrm{~min}$. The dodecane was used as internal standard. The calibration factors of various molecules to dodecane were used as internal standard.

$\mathrm{CO}$ oxidation tests were carried out in a fixed-bed reactor with length of $500 \mathrm{~mm}$ and diameter of $5 \mathrm{~mm}$ at $1 \mathrm{~atm}$ and temperature controlled by an oven. The catalysts were pressured, crushed, sieved into 40-60 mesh, and diluted with 
TABLE 1: Catalytic oxidation of benzyl alcohol, phenylethyl alcohol, cyclohexanol, and 1-hexanol over various catalysts. The substrate conversions and selectivities to the aldehyde/ketone products are presented.

\begin{tabular}{|c|c|c|c|c|c|c|c|c|}
\hline \multirow[b]{2}{*}{ Entry } & \multicolumn{2}{|c|}{ Benzyl alcohol $^{\mathrm{a}}$} & \multicolumn{2}{|c|}{ Phenylethyl alcohol $^{\mathrm{b}}$} & \multicolumn{2}{|c|}{ Cyclohexanol $^{\mathrm{c}}$} & \multicolumn{2}{|c|}{ 1-Hexanol ${ }^{\mathrm{d}}$} \\
\hline & $\begin{array}{c}\text { Conv. } \\
(\%)\end{array}$ & $\begin{array}{l}\text { Sel. } \\
(\%)\end{array}$ & $\begin{array}{c}\text { Conv. } \\
(\%)\end{array}$ & $\begin{array}{l}\text { Sel. } \\
(\%)\end{array}$ & $\begin{array}{c}\text { Conv. } \\
(\%)\end{array}$ & $\begin{array}{l}\text { Sel. } \\
(\%)\end{array}$ & $\begin{array}{c}\text { Conv. } \\
(\%)\end{array}$ & $\begin{array}{l}\text { Sel. } \\
(\%)\end{array}$ \\
\hline $\mathrm{Au} / \mathrm{C}$ & 16.2 & 98.8 & 43.3 & $>99.5$ & 6.3 & $>99.5$ & 4.4 & 97.9 \\
\hline $\mathrm{Au} / \mathrm{C}+\mathrm{PVP}^{\mathrm{e}}$ & 35.5 & 98.0 & 66.9 & $>99.5$ & 15.1 & $>99.5$ & 14.1 & 99.1 \\
\hline $\mathrm{Au} / \mathrm{BN}$ & 10.0 & 99.0 & 21.2 & $>99.5$ & 4.2 & $>99.5$ & 4.9 & 99.0 \\
\hline $\mathrm{Au} / \mathrm{BN}+\mathrm{PVP}^{\mathrm{e}}$ & 21.9 & 99.5 & 29.0 & $>99.5$ & 10.0 & $>99.5$ & 17.1 & 98.4 \\
\hline $\mathrm{Au} / \mathrm{TiO}_{2}$ & 29.1 & 97.9 & 66.6 & $>99.5$ & 16.1 & $>99.5$ & 9.9 & 98.9 \\
\hline $\mathrm{Au} / \mathrm{TiO}_{2}+\mathrm{PVP}^{\mathrm{e}}$ & 55.0 & 96.5 & 75.6 & $>99.5$ & 31.9 & $>99.5$ & 21.2 & 98.3 \\
\hline $\mathrm{Au} / \mathrm{SBA}-15$ & 32.1 & 99.0 & 70.0 & $>99.5$ & 11.0 & $>99.5$ & 11.0 & 98.9 \\
\hline $\mathrm{Au} / \mathrm{SBA}-15^{\mathrm{f}}$ & 58.1 & 99.0 & 84.2 & $>99.5$ & & & & \\
\hline $\mathrm{Au} / \mathrm{SBA}-15^{\mathrm{g}}$ & 66.0 & 99.4 & 87.3 & $>99.5$ & & & & \\
\hline $\mathrm{Au} / \mathrm{SBA}-15+\mathrm{PVP}^{\mathrm{e}}$ & 59.0 & 99.0 & 91.3 & $>99.5$ & 22.4 & $>99.5$ & 25.0 & 99.2 \\
\hline $\mathrm{Au} / \mathrm{SBA}-15+\mathrm{PVP}^{\mathrm{fh}}$ & 79.6 & 99.1 & 97.5 & $>99.5$ & & & & \\
\hline $\mathrm{Au} / \mathrm{SBA}-15+\mathrm{PVP}^{\mathrm{gi}}$ & 93.2 & 98.0 & 99.0 & $>99.5$ & & & & \\
\hline
\end{tabular}

${ }^{a}$ Reaction conditions: $1 \mathrm{mmol}$ of alcohol, $3 \mathrm{~mL}$ of toluene solvent, 5 bar of oxygen, $30 \mathrm{mg}$ of catalyst, $100^{\circ} \mathrm{C}, 3 \mathrm{~h} ;{ }^{b}$ Reaction conditions: $1 \mathrm{mmol}$ of alcohol, $3 \mathrm{~mL}$ of toluene solvent, $30 \mathrm{mg}$ of catalyst, $80^{\circ} \mathrm{C}, 3 \mathrm{~h} ;{ }^{\mathrm{c}}$ Reaction conditions: $1 \mathrm{mmol}$ of alcohol, $3 \mathrm{~mL}$ of toluene solvent, $30 \mathrm{mg}$ of catalyst, $100^{\circ} \mathrm{C}, 5 \mathrm{~h} ;{ }^{\mathrm{d}} \mathrm{Reaction}$ conditions: $1 \mathrm{mmol}$ of alcohol, $3 \mathrm{~mL}$ of p-xylene solvent, $30 \mathrm{mg}$ of catalyst, $120^{\circ} \mathrm{C}, 5 \mathrm{~h} ;{ }^{\mathrm{e}} 15 \mathrm{mg}$ of PVP was physically mixed with the catalysts; ${ }^{\mathrm{f}} 60 \mathrm{mg}$ of catalyst was used. The molar ratio of S/C (substrate/catalyst) is about $192 ;{ }^{\mathrm{g}} 120 \mathrm{mg}$ of catalyst was used. The molar ratio of S/C (substrate/catalyst) is about $96 ;{ }^{\mathrm{h}} 30 \mathrm{mg}$ of PVP was added; ${ }^{\mathrm{i}} 60 \mathrm{mg}$ of PVP was added.

quartz in the volume ratio of $1 / 1$. The catalysts localized in the middle part of the reactor were pretreated with $20 \% \mathrm{O}_{2} / \mathrm{He}$ at $120^{\circ} \mathrm{C}$ for $1 \mathrm{~h}$. The gas component of $1 \% \mathrm{CO} / 19 \% \mathrm{O}_{2} / 80 \%$ He was used as feed with GHSV at $70000 \mathrm{~mL} / \mathrm{g}_{\mathrm{Au}} / \mathrm{h}$. The productive gas was analyzed by a chromatograph equipped with thermal conductivity detector (TCD) and a column (TDX-1) at constant temperature of $90^{\circ} \mathrm{C}$.

The oxidation of ethanol was carried out in a continuousflow fixed-bed reactor with length of $400 \mathrm{~mm}$ and diameter of $6 \mathrm{~mm}$. Pure oxygen was used as oxidant. Ethanol was introduced with a pump and the flow rate of oxygen was controlled by a flow instrument. The reactants and products were collected by cold trap and then analyzed by a gas chromatography equipped with FID detector and Agilent HP6890 Gas chromatography-mass spectrometry. The oxidation was performed with $30 \mathrm{mg}$ of catalyst with 40-60 mesh diluted with $0.15 \mathrm{~g}$ of quartz sands (40-60 mesh), ethanol inlet rate of $0.1 \mathrm{~mL} / \mathrm{h}$, and $\mathrm{O}_{2}$ flow rate of $6.8 \mathrm{~mL} / \mathrm{min}$.

\section{Results and Discussion}

The $\mathrm{Au} / \mathrm{C}, \mathrm{Au} / \mathrm{BN}, \mathrm{Au} / \mathrm{TiO}_{2}$, and $\mathrm{Au} / \mathrm{SBA}-15$ catalysts were synthesized according to the impregnation method using activated carbon, boron nitride, anatase, and mesoporous SBA-15 as support. By ICP analysis, the Au loading on Au/C, $\mathrm{Au} / \mathrm{BN}, \mathrm{Au} / \mathrm{TiO}_{2}$, and $\mathrm{Au} / \mathrm{SBA}-15$ is established to be 1.6, 1.6, 1.7 , and $1.6 \mathrm{wt} \%$, respectively.

The investigation in catalytic activity of these catalysts starts from the catalytic oxidation of various alcohols including benzyl alcohol, phenylethyl alcohol, cyclohexanol, and 1-hexanol. The catalytic data of various catalysts are summarized in Table 1. Interestingly, the PVP-modified Au catalysts (Figure 1, the presence of PVP on the Au sample was confirmed by thermogravimetry analysis) always exhibit higher conversions than the catalysts without PVP. For example, in the oxidation of benzyl alcohol, $\mathrm{Au} / \mathrm{C}, \mathrm{Au} / \mathrm{BN}$, $\mathrm{Au} / \mathrm{TiO}_{2}$, and $\mathrm{Au} / \mathrm{SBA}-15$ give benzyl alcohol conversions at $16.2,10.0,29.1$, and 32.1\%, respectively. After adding small amount of PVP to the reaction liquor, the conversions of benzyl alcohol over PVP-modified $\mathrm{Au} / \mathrm{C}, \mathrm{Au} / \mathrm{BN}, \mathrm{Au} / \mathrm{TiO}_{2}$, and Au/SBA-15 could reach as high as 35.5, 21.9, 55.0, and $59.0 \%$, respectively. Notably, the only difference between each catalyst in the couple (e.g., Au/SBA-15 and PVP-modified $\mathrm{Au} / \mathrm{SBA}-15$ catalysts) is the presence or absence of PVP species, which can completely avoid the influence of $\mathrm{Au}$ nanoparticle diameters for the catalytic reactions. Figure 1 shows the turnover frequencies (TOFs) over various catalysts in the oxidation of benzyl alcohol. The PVP-modified catalysts exhibit higher TOFs than the PVP-free ones, indicating the important role of PVP in enhancing the catalytic activities. Notably, this strategy in enhancing the catalytic activities of $\mathrm{Au}$ catalysts by PVP modification not only is limited to the oxidation of alcohols but also can be extended to the oxidation of other aromatic alcohols of phenylethyl alcohol and aliphatic alcohols of cyclohexanol and 1-hexanol. In these cases, significant enhanced catalytic activity and alcohol conversion could be obtained by simply adding PVP in the reaction liquor.

Notably, it is worth noting that the PVP enhanced the activities of $\mathrm{Au} / \mathrm{SBA}-15$ and $\mathrm{Au} / \mathrm{C}$ more significantly than the activities of $\mathrm{Au} / \mathrm{BN}$ and $\mathrm{Au} / \mathrm{TiO}_{2}$ (Figure 2). Considering the same amount of PVP was used in the reaction liquor of different catalysts, we rationally studied the adsorption of PVP on the solid catalysts in water solvent. Taking Au/SBA15 and $\mathrm{Au} / \mathrm{TiO}_{2}$ as an example, the Au/SBA-15 adsorbed PVP continuously with the adsorption time, giving an adsorption 


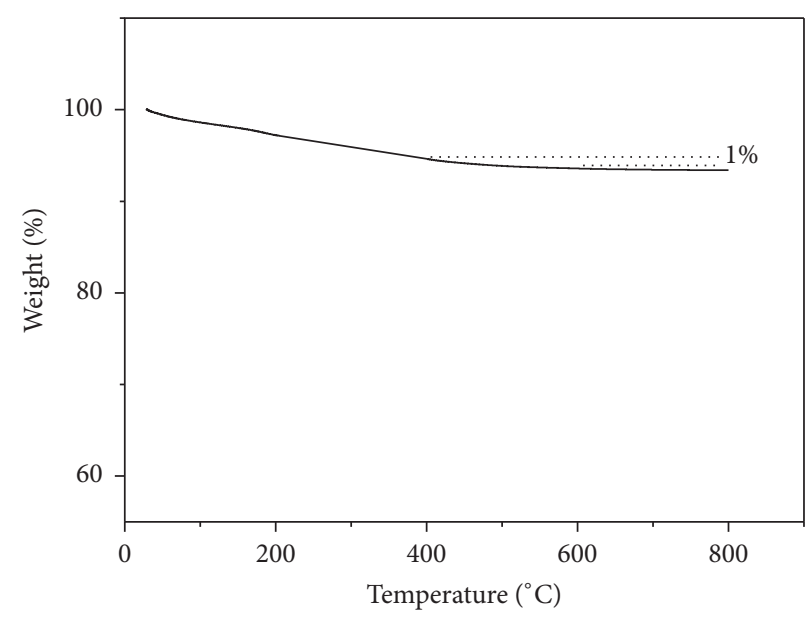

(a)

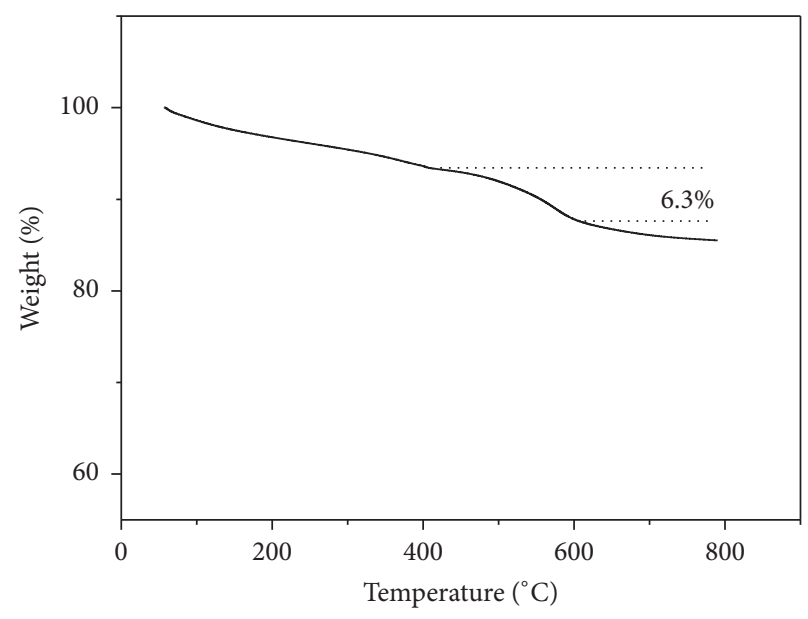

(b)

Figure 1: TG curves of the $\mathrm{Au} / \mathrm{TiO}_{2}$ before (a) and after (b) PVP modification. The significant weight decrease at 400 to $600{ }^{\circ} \mathrm{C}$ is attributed to the removal of PVP species. In contrast, the as-synthesized $\mathrm{Au} / \mathrm{TiO}_{2}$ gives the weight decrease at $\sim 1 \%$ in the same temperature region, demonstrating the lack of PVP.

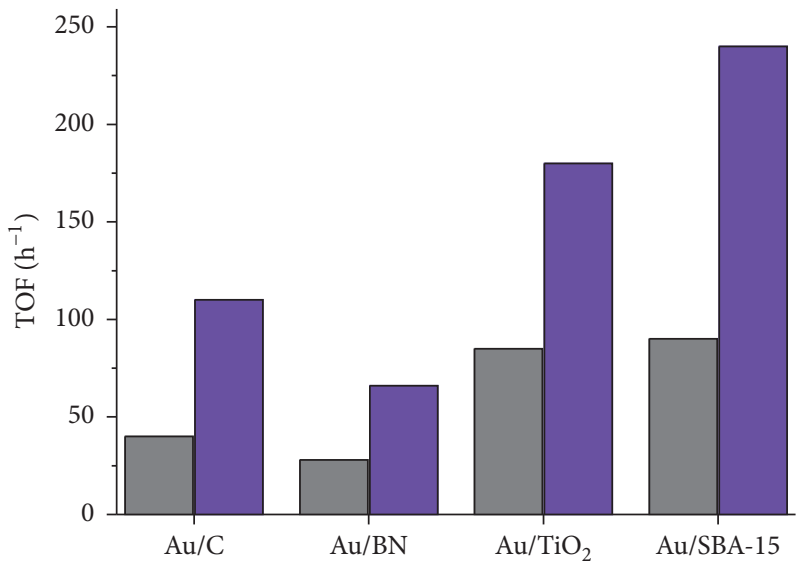

FIGURE 2: TOFs of various catalysts in the oxidation of benzyl alcohol. The gray and purple correspond to the as-synthesized and PVP-modified catalysts, respectively. Reaction conditions: $3 \mathrm{mmol}$ of alcohol, $3 \mathrm{~mL}$ of toluene solvent, 5 bar of oxygen, and $10 \mathrm{mg}$ of catalyst, $100^{\circ} \mathrm{C}, 20 \mathrm{~min}$.

amount at $\sim 125 \mathrm{mg} / \mathrm{g}$ in $60 \mathrm{~min}$. In contrast, $\mathrm{Au} / \mathrm{TiO}_{2}$ only adsorbed a small amount at $\sim 12 \mathrm{mg} / \mathrm{g}$ (Figure $3(\mathrm{a})$ ). This phenomenon might be attributed to the rich mesoporosity of Au/SBA-15, which benefits the adsorption and enrichment of PVP in the mesopores. Therefore, the Au nanoparticles localized in the mesopores of SBA-15, as present in Figure 3(b) where the Au nanoparticle diameters are calculated to be at $2-10 \mathrm{~nm}$ with mean size at $3.6 \mathrm{~nm}$, prefer to be modified by PVP.

Furthermore, we reasonably adjusted the molar ratio of substrate and PVP-modified Au/SBA-15 catalyst in the oxidation of benzyl alcohol and phenylethyl alcohol (Table 1). Clearly, in both cases, the alcohol conversions significantly increased with more Au species in the reaction system, which could reach as high as $93.2 \%$ for benzyl alcohol and $99.0 \%$ for phenylethyl alcohol. But the PVP-modified catalysts are always more active than the PVP-free ones, demonstrating the positive role of PVP in promoting the reaction.

These results motivated us to study the role of PVP interacting with Au nanoparticles. Figure 4 shows the Au4f XPS spectra of Au/SBA-15 and PVP-modified Au/SBA-15 samples. The spectrum of Au/SBA-15 exhibits Au4f binding energy at $84.1 \mathrm{eV}$, which is the typical binding energy of metallic $\mathrm{Au}[12,36]$. Interestingly, after PVP-modification treatment, the Au4f binding energy is $83.4 \mathrm{eV}$, with a shift of $0.7 \mathrm{eV}$ from the metallic Au. Considering the two samples have the same SBA-15 support and Au nanoparticles, the different binding energy should be reasonably attributed to the PVP additive. The negatively charged Au is known to be very active in the activation of molecule oxygen [37-39], thus exhibiting higher activities than the conventional PVP-free catalysts in the oxidation reactions.

Motivated by the successes in oxidation of alcohols in liquid phase, we then carried out the aerobic oxidation of ethanol in gas phase in a fixed-bed reactor, which is an important reaction for obtaining acetaldehyde. Figure 5 shows the dependence of ethanol conversion on time over as-synthesized and PVP-modified Au/SBA-15 catalysts. At a reaction temperature of $120^{\circ} \mathrm{C}$ (Figure 5(a)), which is a relatively low temperature for ethanol oxidation [40-42], the $\mathrm{Au} / \mathrm{SBA}-15$ catalyst is inactive for the reaction. Interestingly, the PVP-modified SBA-15 exhibits ethanol conversion at $12.4 \%$ with acetaldehyde (selectivity at $>98.0$ ) as a major product. In a reaction period of $11 \mathrm{~h}$, the PVP-modified SBA15 catalyst exhibits a constant conversion at $\sim 12.0 \%$ with $>98.0 \%$ selectivity of acetaldehyde. These results indicate the positive effect of PVP in enhancing the catalytic activity of $\mathrm{Au}$ catalyst in ethanol oxidation. When the reactions were performed at high temperature of $170^{\circ} \mathrm{C}$, the ethanol conversions are higher than those at $120^{\circ} \mathrm{C}$, where the PVPmodified Au/SBA-15 catalyst always exhibits higher ethanol 


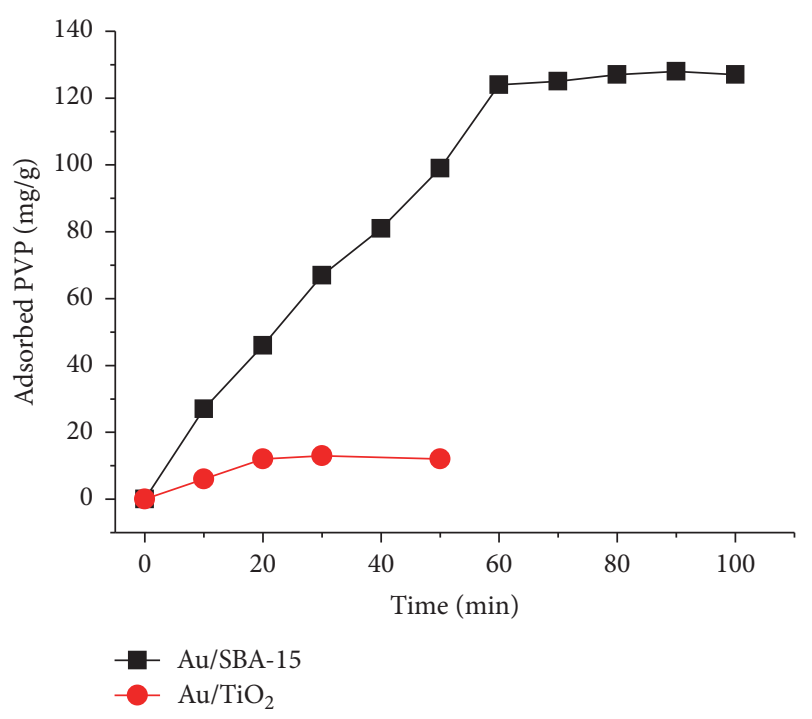

(a)

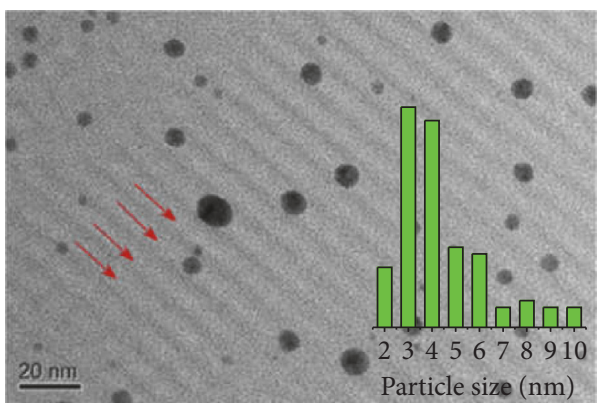

(b)

Figure 3: (a) Dependence of adsorption amount of PVP over Au/SBA-15 and $\mathrm{Au} / \mathrm{TiO}_{2}$ catalysts. (b) High-resolution TEM image of Au/SBA15. The red arrows highlight the mesopores.

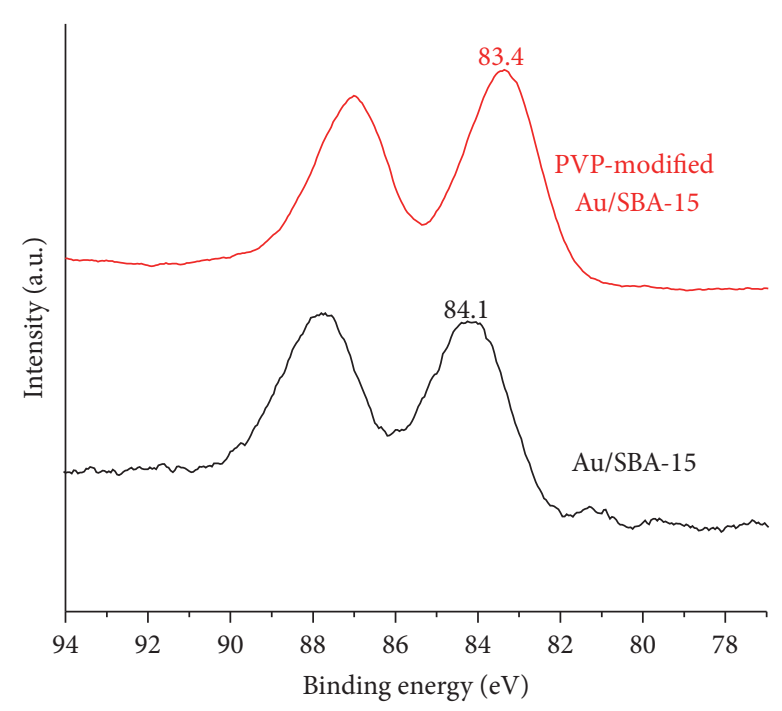

FIgUre 4: Au4f XPS spectra of Au/SBA-15 and PVP-modified $\mathrm{Au} / \mathrm{SBA}-15$.

conversion than the PVP-free Au/SBA-15, further confirming the promotion role of PVP. Notably, in the reaction after $12 \mathrm{~h}$ at $120^{\circ} \mathrm{C}$ or $6 \mathrm{~h}$ at $170^{\circ} \mathrm{C}$, a significant decrease in ethanol conversion could be observed, which might be due to the leaching of PVP species during the reaction process. After retreatment of the catalyst using PVP, the catalyst activity was easily regenerated.

Furthermore, we extended the method of using PVP to enhance the catalytic activity to the oxidation of $\mathrm{CO}$ (Figure 6), which is an important reaction and widely investigated over various Au nanocatalysts. The silica supported Au nanoparticles are known as poorly active catalyst for the reaction because of the inert silica support. Similar phenomenon could also be observed in the Au/SBA-15 catalyst, which exhibits very low $\mathrm{CO}$ conversion $(<5 \%)$ at even $150^{\circ} \mathrm{C}$. Interestingly, the $\mathrm{CO}$ conversion could be significantly enhanced after treating Au/SBA-15 with PVP, giving $12.8 \%$ at $150^{\circ} \mathrm{C}$. Although this performance is not so good as the highly active metal oxides support Au nanoparticles in literature [43-45], it still gives clear evidence to confirm the positive effect of PVP in promoting the Au-catalyzed oxidation reaction, in good agreement with the results obtained from alcohol oxidation.

\section{Conclusions}

In summary, we demonstrate that adding PVP could effectively enhance the catalytic activity of supported Au nanoparticles, because the PVP could electronically interact with $\mathrm{Au}$ to form high active $\mathrm{Au}$ sites for molecular oxygen. Other catalysts with PVP modification are mostly soluble ones, which have significant disadvantages in separation and regeneration, particularly for the noble metal catalysts. Our work extended the concept of PVP modification and promotion to the supported Au nanoparticle catalysts, remarkably enhancing the activity of supported metal catalysts. The features of the PVP-modification method, including low cost, being easily available, general usability, and harmlessness of PVP, make it potentially important for wide applications. Although the PVP might leach during the reaction recycles, it could not pollute the products because the PVP could be easily separated from the product molecules due to its high molecule weight. The method involved in this work might be potentially important for developing more catalysts with enhanced activities in the future.

\section{Conflicts of Interest}

The authors declare that they have no conflicts of interest. 


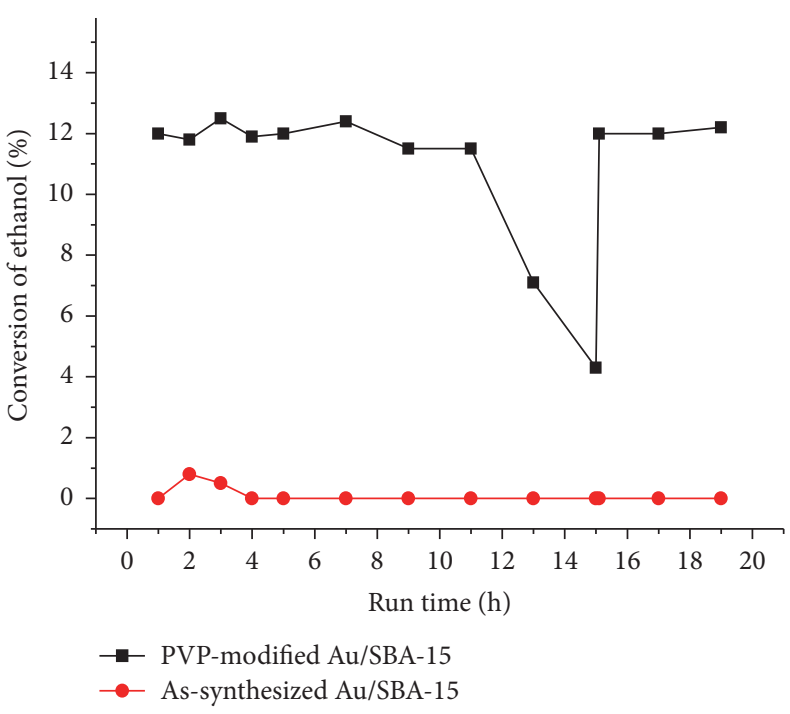

(a)

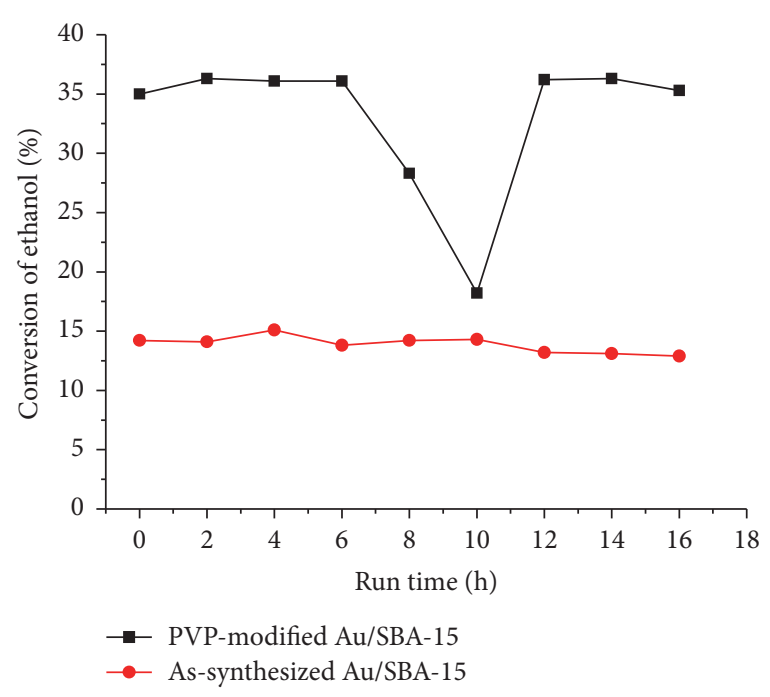

(b)

FIGURE 5: Catalytic data in aerobic oxidation of ethanol over the Au catalysts at (a) 120 and (b) $170^{\circ} \mathrm{C}$. In the case of PVP-modified Au/SBA-15, the deactivated catalyst was treated with PVP again after reaction for $15 \mathrm{~h}$ at $120^{\circ} \mathrm{C}$ and $10 \mathrm{~h}$ at $170^{\circ} \mathrm{C}$ and further used in the reaction. The acetaldehyde selectivities are over $98 \%$ at $120^{\circ} \mathrm{C}$ and over $95 \%$ at $170^{\circ} \mathrm{C}$ with acetic acid as by-product.

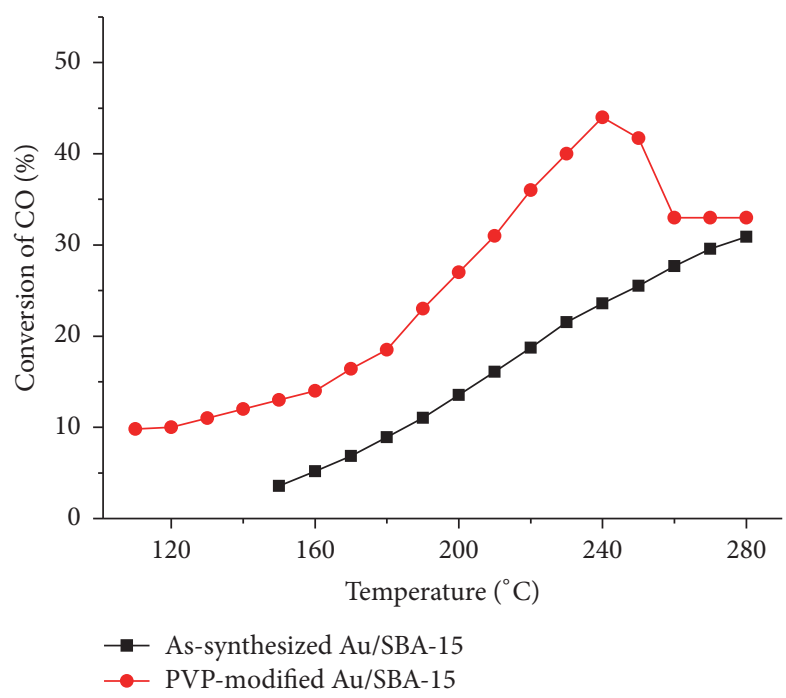

FIgure 6: Catalytic oxidation of CO over the Au catalysts.

\section{Acknowledgments}

This work was supported by the National Key Technology R\&D Program of China (no. 2016YFB0401103), National Natural Science Foundation of China (no. 51672103), and Natural Science Foundation of Jilin Province Department of Education (nos. 2014238 and 2015279).

\section{References}

[1] G. J. Hutchings, "Vapor phase hydrochlorination of acetylene: correlation of catalytic activity of supported metal chloride catalysts," Journal of Catalysis, vol. 96, no. 1, pp. 292-295, 1985.
[2] M. Haruta, "Size- and support-dependency in the catalysis of gold," Catalysis Today, vol. 36, no. 2, pp. 153-166, 1997.

[3] G. J. Hutchings and M. Haruta, "A golden age of catalysis: a perspective," Applied Catalysis A: General, vol. 291, no. 1-2, pp. 2-5, 2005.

[4] M. Haruta, "Catalysis: gold rush," Nature, vol. 437, no. 7062, pp. 1098-1099, 2005.

[5] T. Ishida and M. Haruta, "Gold catalysts: towards sustainable chemistry," Angewandte Chemie - International Edition, vol. 46, no. 38, pp. 7154-7156, 2007.

[6] A. S. K. Hashmi and G. J. Hutchings, "Gold catalysis," Angewandte Chemie - International Edition, vol. 45, no. 47, pp. 78967936, 2006.

[7] H. Tsunoyama, H. Sakurai, Y. Negishi, and T. Tsukuda, "Sizespecific catalytic activity of polymer-stabilized gold nanoclusters for aerobic alcohol oxidation in water," Journal of the American Chemical Society, vol. 127, no. 26, pp. 9374-9375, 2005.

[8] M. Stratakis and H. Garcia, "Catalysis by supported gold nanoparticles: beyond aerobic oxidative processes," Chemical Reviews, vol. 112, no. 8, pp. 4469-4506, 2012.

[9] S.-I. Naya, M. Teranishi, R. Aoki, and H. Tada, "Fermi level control of gold nanoparticle by the support: activation of the catalysis for selective aerobic oxidation of alcohols," Journal of Physical Chemistry C, vol. 120, no. 23, pp. 12440-12445, 2016.

[10] C. Lavenn, A. Demessence, and A. Tuel, " $\mathrm{Au}_{25}\left(\mathrm{SPh}-\mathrm{pNH} \mathrm{N}_{2}\right)_{17}$ nanoclusters deposited on SBA-15 as catalysts for aerobic benzyl alcohol oxidation," Journal of Catalysis, vol. 322, pp. 130-138, 2015.

[11] L. Wang, W. Zhang, D. Sheng Su, X. Meng, and F.-S. Xiao, "Supported Au nanoparticles as efficient catalysts for aerobic homocoupling of phenylboronic acid," Chemical Communications, vol. 48, no. 44, pp. 5476-5478, 2012.

[12] L. Wang, H. Wang, W. Zhang et al., "Aerobic homocoupling of phenylboronic acid on $\mathrm{Mg}$-Al mixed-oxides-supported $\mathrm{Au}$ nanoparticles," Journal of Catalysis, vol. 298, pp. 186-197, 2013. 
[13] G. Li, C. Liu, Y. Lei, and R. Jin, " $\mathrm{Au}_{25}$ nanocluster-catalyzed Ullmann-type homocoupling reaction of aryl iodides," Chemical Communications, vol. 48, no. 98, pp. 12005-12007, 2012.

[14] Q. Sun, L. Cai, H. Ma, C. Yuan, and W. Xu, "Dehalogenative homocoupling of terminal alkynyl bromides on $\mathrm{Au}(111)$ : incorporation of acetylenic scaffolding into surface nanostructures," ACS Nano, vol. 10, no. 7, pp. 7023-7030, 2016.

[15] X. Zhang, H. Shi, and B.-Q. Xu, "Catalysis by Gold: Isolated Surface $\mathrm{Au}^{3+}$ Ions are Active Sites for Selective Hydrogenation of 1,3-Butadiene over $\mathrm{Au} / \mathrm{ZrO}_{2}$ Catalysts," Angewandte Chemie International Edition, vol. 44, no. 43, pp. 7132-7135, 2005.

[16] X. Liu, C.-Y. Mou, S. Lee, Y. Li, J. Secrest, and B. W.-L. Jang, "Room temperature $\mathrm{O}_{2}$ plasma treatment of $\mathrm{SiO}_{2}$ supported $\mathrm{Au}$ catalysts for selective hydrogenation of acetylene in the presence of large excess of ethylene," Journal of Catalysis, vol. 285, no. 1, pp. 152-159, 2012.

[17] N. Perret, X. Wang, J. J. Delgado et al., "Selective hydrogenation of benzoic acid over Au supported on $\mathrm{CeO}_{2}$ and $\mathrm{Ce}_{0.62} \mathrm{Zr}_{0.38} \mathrm{O}_{2}$ : formation of benzyl alcohol," Journal of Catalysis, vol. 317, pp. 114-125, 2014.

[18] J. Ohyama, A. Esaki, Y. Yamamoto, S. Arai, and A. Satsuma, "Selective hydrogenation of 2-hydroxymethyl-5-furfural to 2,5bis(hydroxymethyl)furan over gold sub-nano clusters," RSC Advances, vol. 3, no. 4, pp. 1033-1036, 2013.

[19] C. Milone, C. Crisafulli, R. Ingoglia, L. Schipilliti, and S. Galvagno, "A comparative study on the selective hydrogenation of $\alpha, \beta$ unsaturated aldehyde and ketone to unsaturated alcohols on Au supported catalysts," Catalysis Today, vol. 122, no. 3-4, pp. 341-351, 2007.

[20] Y. Niu, L. K. Yeung, and R. M. Crooks, "Size-selective hydrogenation of olefins by Dendrimer-encapsulated palladium nanoparticles," Journal of the American Chemical Society, vol. 123, no. 28, pp. 6840-6846, 2001.

[21] S. A. Nikolaev and V. V. Smirnov, "Synergistic and size effects in selective hydrogenation of alkynes on gold nanocomposites," Catalysis Today, vol. 147, pp. S336-S341, 2009.

[22] Y. Liu, H. Tsunoyama, T. Akita, S. Xie, and T. Tsukuda, "Aerobic oxidation of cyclohexane catalyzed by size-controlled au clusters on hydroxyapatite: size effect in the sub-2 $\mathrm{nm}$ regime," ACS Catalysis, vol. 1, no. 1, pp. 2-6, 2011.

[23] M. Comotti, W.-C. Li, B. Spliethoff, and F. Schüth, "Support effect in high activity gold catalysts for CO oxidation," Journal of the American Chemical Society, vol. 128, no. 3, pp. 917-924, 2006.

[24] L. K. Ono and B. Roldán-Cuenya, "Effect of interparticle interaction on the low temperature oxidation of CO over sizeselected Au nanocatalysts supported on ultrathin TiC films," Catalysis Letters, vol. 113, no. 3-4, pp. 86-94, 2007.

[25] M. Turner, V. B. Golovko, O. P. H. Vaughan et al., "Selective oxidation with dioxygen by gold nanoparticle catalysts derived from 55-atom clusters," Nature, vol. 454, no. 7207, pp. 981-983, 2008.

[26] L. Wang, Y. Zhu, J.-Q. Wang et al., "Two-dimensional gold nanostructures with high activity for selective oxidation of carbon-hydrogen bonds," Nature Communications, vol. 6, article no. 6957, 2015.

[27] H. Li, Z. Bian, J. Zhu, Y. Huo, H. Li, and Y. Lu, "Mesoporous $\mathrm{Au} / \mathrm{TiO}_{2}$ nanocomposites with enhanced photocatalytic activity," Journal of the American Chemical Society, vol. 129, no. 15, pp. 4538-4539, 2007.
[28] E. Genty, R. Cousin, C. Gennequin, S. Capelle, A. Aboukaïs, and S. Siffert, "Investigation of Au/hydrotalcite catalysts for toluene total oxidation," Catalysis Today, vol. 176, no. 1, pp. 116-119, 2011.

[29] P. Pachfule, S. Kandambeth, D. Díaz Díaz, and R. Banerjee, "Highly stable covalent organic framework-Au nanoparticles hybrids for enhanced activity for nitrophenol reduction," Chemical Communications, vol. 50, no. 24, pp. 3169-3172, 2014.

[30] Y. Mikami, A. Dhakshinamoorthy, M. Alvaro, and H. Garcia, Catalysis Science Technology, vol. 3, pp. 58-69, 2013.

[31] Z. Huang, F. Li, B. Chen, and G. Yuan, Green Chemistry, vol. 17, pp. 2325-2329, 2015.

[32] H. Song, R. M. Rioux, J. D. Hoefelmeyer et al., "Hydrothermal growth of mesoporous SBA-15 silica in the presence of PVPstabilized Pt nanoparticles: Synthesis, characterization, and catalytic properties," Journal of the American Chemical Society, vol. 128, no. 9, pp. 3027-3037, 2006.

[33] D. Zhao, Q. Huo, J. Feng, B. F. Chmelka, and G. D. Stucky, "Nonionic triblock and star diblock copolymer and oligomeric sufactant syntheses of highly ordered, hydrothermally stable, mesoporous silica structures," Journal of the American Chemical Society, vol. 120, no. 24, pp. 6024-6036, 1998.

[34] L. Wang, J. Zhang, H. Wang et al., "Activity and selectivity in nitroarene hydrogenation over $\mathrm{Au}$ nanoparticles on the edge/corner of anatase," ACS Catalysis, vol. 6, no. 7, pp. 41104116, 2016.

[35] Q. Tian, W. Wong, Y. Xu et al., "Immobilisation of quantum dots by bio-orthogonal PCR amplification and labelling for direct gene detection and quantitation," Chemical Communications, vol. 48, no. 44, pp. 5467-5469, 2012.

[36] L. Wang, H. Wang, A. E. Rice et al., "Design and preparation of supported Au catalyst with enhanced catalytic activities by rationally positioning Au nanoparticles on anatase," Journal of Physical Chemistry Letters, vol. 6, no. 12, pp. 2345-2349, 2015.

[37] S. Nishimura, Y. Yakita, M. Katayama, K. Higashimine, and K. Ebitani, "The role of negatively charged Au states in aerobic oxidation of alcohols over hydrotalcite supported AuPd nanoclusters," Catalysis Science and Technology, vol. 3, no. 2, pp. 351359, 2013.

[38] H. Tsunoyama, N. Ichikuni, H. Sakurai, and T. Tsukuda, "Effect of electronic structures of au clusters stabilized by poly(N-vinyl2-pyrrolidone) on aerobic oxidation catalysis," Journal of the American Chemical Society, vol. 131, no. 20, pp. 7086-7093, 2009.

[39] Z. Jiang, W. Zhang, L. Jin et al., "Direct XPS evidence for charge transfer from a reduced rutile $\mathrm{TiO}_{2}(110)$ surface to Au clusters," Journal of Physical Chemistry C, vol. 111, no. 33, pp. 12434-12439, 2007.

[40] P. P. Lopes, D. Strmcnik, J. S. Jirkovsky, J. G. Connell, V. Stamenkovic, and N. Markovic, "Double layer effects in electrocatalysis: The oxygen reduction reaction and ethanol oxidation reaction on $\operatorname{Au}\left(\begin{array}{lll}1 & 1 & 1\end{array}\right), \operatorname{Pt}\left(\begin{array}{lll}1 & 1 & 1\end{array}\right)$ and $\operatorname{Ir}\left(\begin{array}{lll}1 & 1 & 1\end{array}\right)$ in alkaline media containing $\mathrm{Na}$ and Li cations," Catalysis Today, vol. 262, pp. 4147, 2016.

[41] H. Wu, H. Li, Y. Zhai, X. Xu, and Y. Jin, Adv. Mater, vol. 24, pp. 1594-1597, 2012.

[42] C. H. Christensen, B. Jørgensen, J. Rass-Hansen et al., "Formation of acetic acid by aqueous-phase oxidation of ethanol with air in the presence of a heterogeneous gold catalyst," Angewandte Chemie - International Edition, vol. 45, no. 28, pp. 4648-4651, 2006.

[43] J. Saavedra, H. A. Doan, C. J. Pursell, L. C. Grabow, and B. D. Chandler, "The critical role of water at the gold-titania interface 
in catalytic CO oxidation," Science, vol. 345, no. 6204, pp. 15991602, 2014.

[44] L. Li, A. Wang, B. Qiao et al., "Origin of the high activity of $\mathrm{Au} / \mathrm{FeOx}$ for low-temperature CO oxidation: Direct evidence for a redox mechanism," Journal of Catalysis, vol. 299, pp. 90100, 2013.

[45] D. Widmann and R. J. Behm, "Activation of molecular oxygen and the nature of the active oxygen species for co oxidation on oxide supported au catalysts," Accounts of Chemical Research, vol. 47, no. 3, pp. 740-749, 2014. 

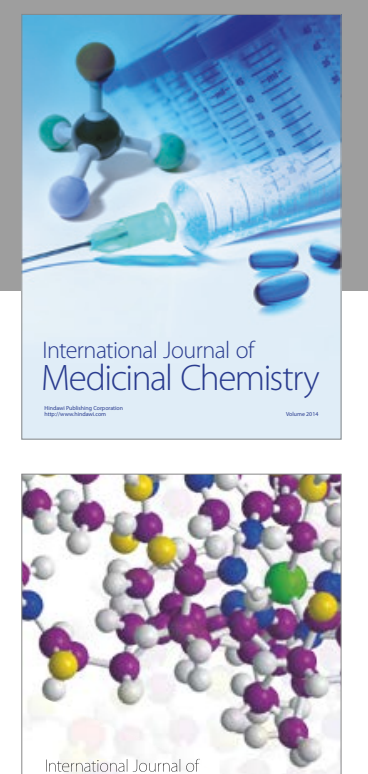

Carbohydrate Chemistry

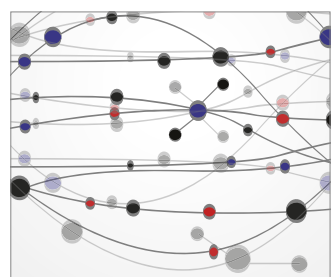

The Scientific World Journal
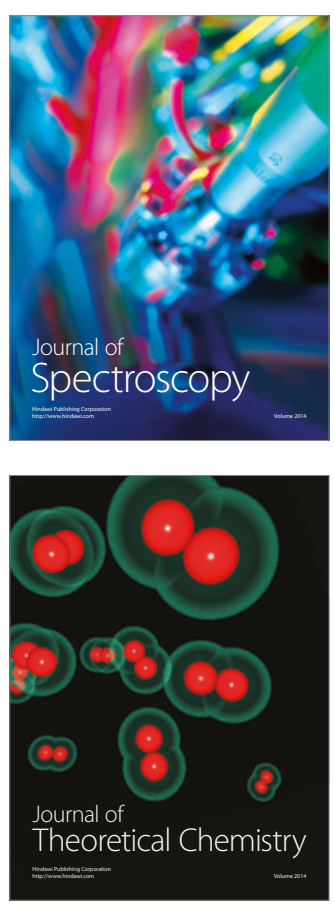
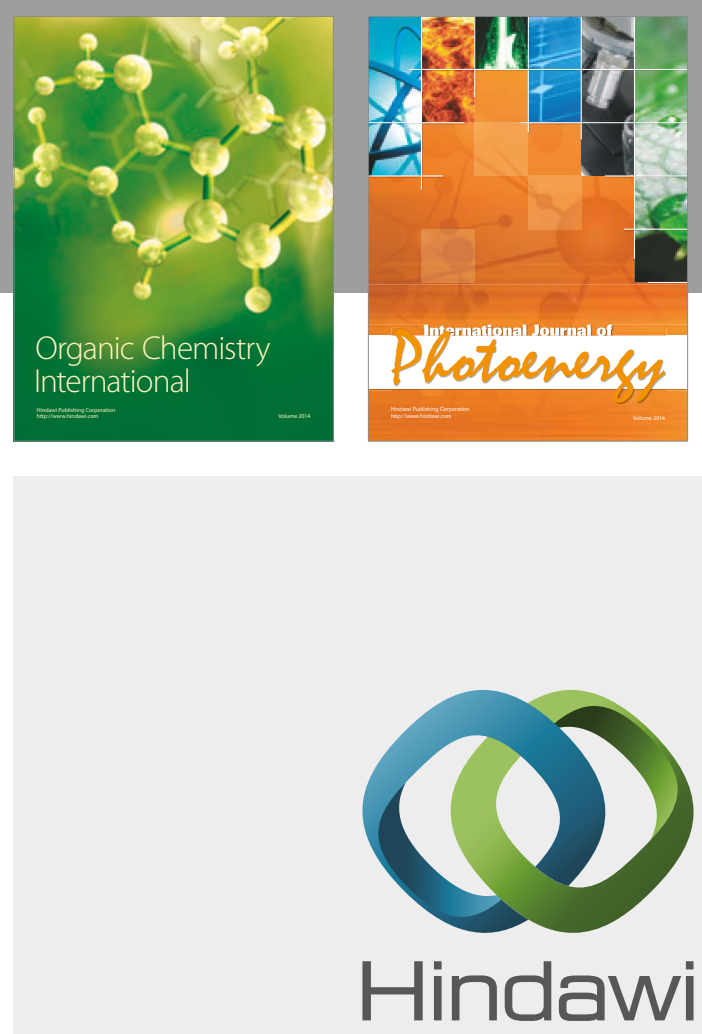

Submit your manuscripts at

https://www.hindawi.com

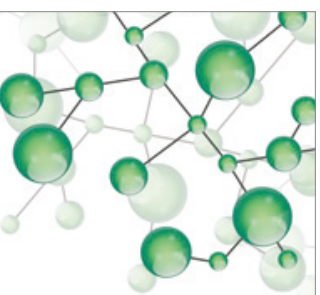

International Journal of

Inorganic Chemistry

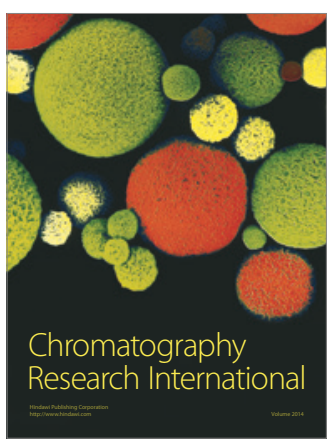

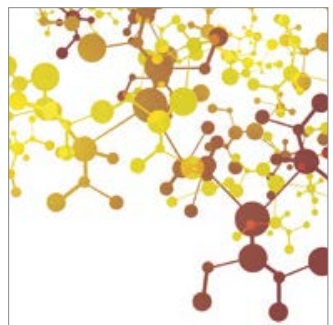

Applied Chemistry
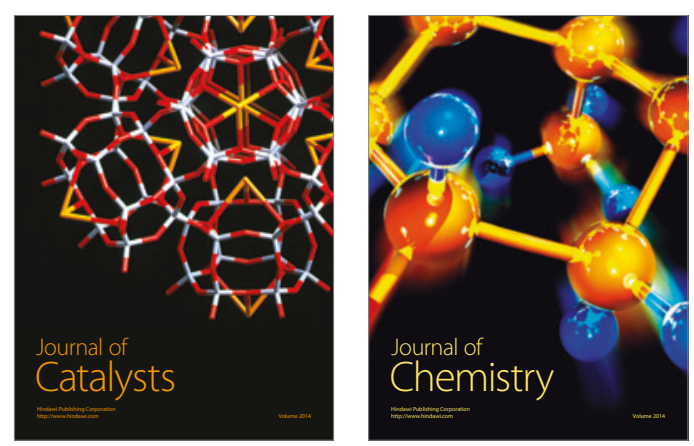
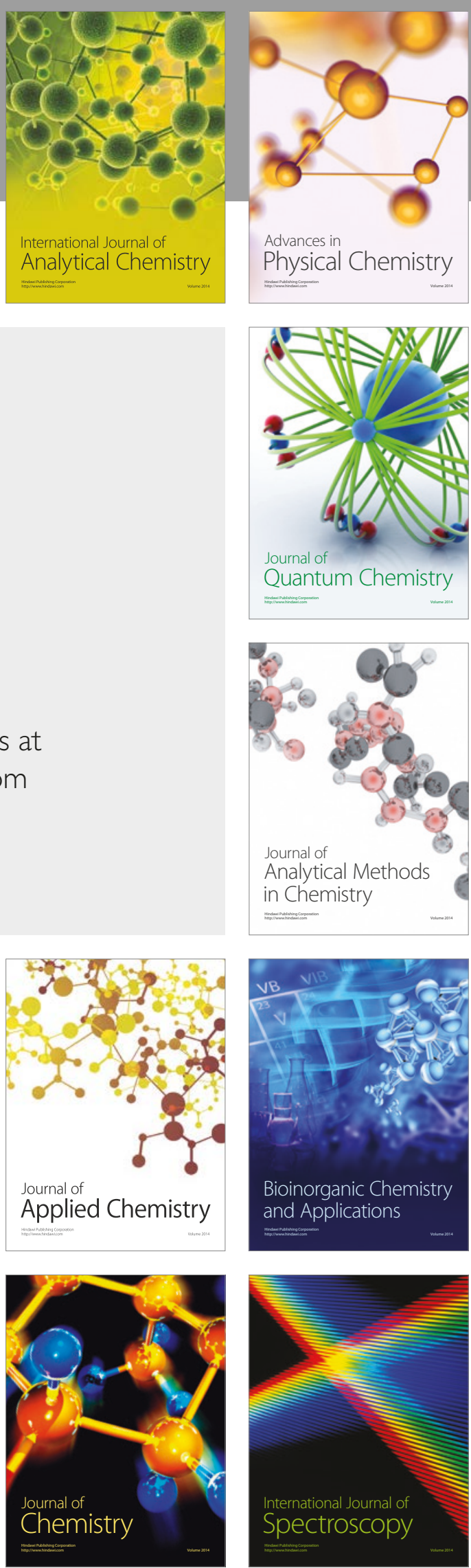